IOSR Journal of Engineering

e-ISSN: 2250-3021, p-ISSN: 2278-8719,

Vol. 2, Issue 12 (Dec. 2012), ||V2|| PP 01-15

\title{
Analysis of the dynamic characteristics of a single- pressure combined-cycle power plant
}

\author{
Azam Ghaedi ${ }^{1}$, Keyvan Daneshvar ${ }^{2}$, Yasamin Khazraii ${ }^{3}$

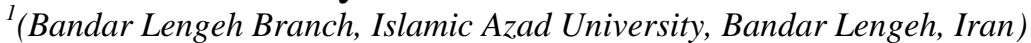 \\ ${ }^{2}$ (Shahrood Branch, Islamic Azad University, Shahrood, Iran) \\ ${ }^{3}$ (Bandar Lengeh Branch, Islamic Azad University, Bandar Lengeh, Iran)
}

\begin{abstract}
Gas/steam combined-cycles are well-known technology for power generation due to their numerous advantages including high efficiency and low environmental emission. A power plant is basically operated on its design conditions or full-load operation. However, it also operates on the socalled off-design conditions due to some conditions like power load variation, process requirements or even start-up and shut down. Therefore, the transient behavior of the system should be known for the safe operation and reliable control. The purpose of this paper was investigation of thermodynamic parameters' behavior of single-pressure system due to load reduction of gas turbine as the input data. In this study the transient behavior of the system predicted by dynamic simulation. This simulation was done using mass and energy conservation equations for each component as a control volume. Governing equations set was solved by an appropriate numerical method and the results were illustrated in some figures.
\end{abstract}

Keywords:-Combined-cycle power plant, Dynamic Modeling, Transient Behavior, Heat recovery steam generator (HRSG)

\section{INTRODUCTION}

As the electricity consumption has risen quickly over the past few decades, the number of thermal power plants has increased worldwide. A heat recovery steam generator (HRSG) produces steam by using the heat from exhaust gas of the gas turbine and feeds it to steam turbine. This combination produces electricity more efficiently than either the gas turbine or steam turbine alone which causes a very good ratio of transformed electrical power per $\mathrm{CO}_{2}$ emission. The combined cycle power plants are characterized as the $21^{\text {st }}$ century power generation by their high efficiency and possibility to operate on different load conditions by reason of variation in consumer load [1]. They are particularly suitable for managing peak and cyclic loads, i.e., daily start/stop operations, since their response characteristics are better than those of other conventional power plants such as fossil fuel and nuclear power plants [2].

An increasingly important utilization for the combined-cycle power plants is the compensation of varying electricity feed-in from renewable energy source like wind power. A combination between wind power and other energy sources such as combined cycles with improved load flexibility should be used in order to mitigate the economic effects of wind variability [1].

Although a power plant is basically operated on its design conditions, it also operates on the so called off-design conditions. Therefore, the transient behavior of the system should be well-known for the safe operation and reliable control [3]. So these parameters may be used for estimating thermal and mechanical stresses which are important in HRSG design and operation [4].

Until now various authors studied in field of combined cycle power plants that some of them investigate simulation and dynamic behavior of these power plants: Ahluwalia and his coworker in [5] discusses the dynamic modeling of a gas-fired $60 \mathrm{Mw}$ combined cycle power plant; Kim TS in [2] simulates the transient behavior of a dual-pressure bottoming system for a combined cycle power plant. Kim JH in [6] describes models for transient analysis of heavy duty $150 \mathrm{Mw}$ gas turbines. Also Shin JY performs a dynamic simulation to analyze the transient behavior of a combined-cycle power plant thoroughly in [3]. Additionally Sanaye prepared a developed thermal model for predicting the working conditions of HRSG elements during transient startup procedure in [4]. Also Alobaid investigates start up process of a combined cycle power plant by using both static and dynamic simulation in [1].

In this study single-pressure combined cycle power plant has been designed, mathematically modeled and investigation of its transient behavior has been done. This modeling is useful to analyze the transient behavior of a combined cycle power plant during load reduction of gas turbine of the system. Realizing the transient performance helps us to estimate mechanical and thermal stresses which are important in power plant design and operation. Transient analysis of gas turbine has been done in [6] and its data is directly utilized in 
this paper. Geometric and thermodynamic of bottoming cycle of studied power plant has been performed by the well-known commercial software [7]. Each component of the power plant system is mathematically modeled and then integrated into the unsteady form of conservation equations, and then the governing equations have been solved by Forward Finite Difference method; Computational program of this method written by mathematical software EES [8].

\section{SYSTEM DESCRIPTION}

Generally, combined cycle power plant is composed of gas turbines, heat recovery steam generators (HRSGs), and steam turbines. The gas turbine exhaust gas flows through a HRSG in which thermal energy of the exhaust gas is used for steam production. The HRSG supplies high-pressure (HP) and low-pressure (LP) steam for using in steam turbine and the de-aerator, respectively. Combined cycle power plant may have various configurations according to the number of HRSG pressure levels, de-aerator type, steam turbine type etc. [3].

A schematic diagram of the system of this study can be seen in Fig.1. Designed cycle includes one $150 \mathrm{Mw}$ GE 7F engine, single-pressure type HRSG and an integral self-heating de-aerator with a condensing steam turbine. Feed water supplied from the condenser by the boiler feed pump is heated in LP preheater (LTE) before it enters into the LP drum (LPB). Saturated water in the LP drum is recirculated through the LP evaporator. Steam produced in the LP drum is supplied to the integral self-heating de-aerator. Water is also drawn from LP drum to the HP drum (HPB1) through the HP economizers (HPE1 \& HPE3). Steam is produced in the HP drum and superheated through the HP super heater (HPS3) for electrical power generation. The system design variables are also shown in Fig.1. Also TABLE 1 contains design data of cycle.

\section{COMPONENT MODELS}

Modeling of the whole system has been done by writing mass and energy conservation equations for each component as can be seen bellow.

\section{Gas Turbine}

Transient behavior of a combined cycle power plant may be caused by star-up, shut down or load reduction. In this study, gas turbine of the cycle is imposed to load reduction, so the system shows its transient behavior affected by this load change from full load state to $80 \%$.

For modeling of gas turbine, the necessary data extracted from [6] and variation of gas turbine parameters can be seen in Fig.2, Fig.3 and Fig.4.

\section{Heat Recovery Steam Generator (HRSG)}

HRSG is an important component of combined cycle power plant; Because of its suffering thermal and mechanical stresses that can be important for design and control of whole system.

The flue gas reduction rate $\left(\dot{Q}_{g}\right)$ after passing an HRSG component is expressed as follows:

$$
\dot{Q}_{g}=\dot{m}_{g}\left(h_{g 1}-h_{g 2}\right)\left(1-K_{\text {loss }}\right)
$$

where $\dot{m}_{g}$ indicates the flue gas mass flow rate and $\left(h_{g 1}-h_{g 2}\right)$ is the gas enthalpy reduction. It was assumed that a part of the gas energy was lost through HRSG casing (about $2 \%$ as the typical value for $K_{\text {loss }}$ ).

Also gas energy reduction rate is equal to heat transfer between gas and HRSG element

$$
\dot{Q}_{g}=U_{o} A_{o}\left(\tilde{T}_{g}-\tilde{T}_{m}\right)
$$

where $U_{\mathrm{o}}$ represents the gas side heat transfer coefficient (including convection and radiation effects) and $A_{o}$ is the outer heat transfer surface area. Also $\tilde{T}_{m}$ and $\tilde{T}_{g}$ describe average metal and gas temperature respectively.

$\dot{Q}_{g}$ is absorbed by the tube wall $\left(\dot{Q}_{m},(4)\right)$, fins $\left(\dot{Q}_{f},(5)\right)$, as well as steam in super heaters, water in economizers and the mixture of steam and water in evaporator tubes $\left(\dot{Q}_{w},(7)\right)$ as is shown in the following equation[4]:

$$
\dot{Q}_{g}=\dot{Q}_{m}+\dot{Q}_{f}+\dot{Q}_{w}
$$

The rate of energy absorbed by the metal of HRSG heating element ( $\left.\dot{Q}_{m}\right)$ is expressed as

$$
\dot{Q}_{m}=\frac{M_{m} c_{m}\left(T_{m}^{e}-T_{m}^{i}\right)}{\Delta t}
$$

Also the rate of energy absorbed by fins $\left(\dot{Q}_{f}\right)$ is 


$$
\dot{Q}_{f}=\frac{M_{f} c_{f}\left(T_{f}^{e}-T_{f}^{i}\right)}{\Delta t}
$$

where $M$ and $c$ in (4) and (5) represent mass and specific heat, respectively; Also $T_{m}$ and $T_{f}$ are metal and fin temperature respectively.

Equation (6) predicts an average value for the fin temperature as follows:

$$
T_{f}=T_{w}+0.3 \times\left(T_{g}-T_{w}\right)
$$

where $T_{g}$ and $T_{w}$ are the gas and steam/water temperatures, respectively.

The absorbed energy by steam or water $\left(\dot{Q}_{w}\right)$ can be estimated by the following equation:

$$
\dot{Q}_{w}=\left(\dot{Q}_{\text {out }}-\dot{Q}_{\text {in }}\right)+\dot{Q}_{a c c u m}-\dot{Q}_{b d}
$$

where $\dot{Q}_{\text {out }}$ and $\dot{Q}_{\text {in }}$ are the rate of energy flowing in and out of an HRSG heating element as explained below[4]

$$
\begin{aligned}
\dot{Q}_{\text {out }} & =\dot{m}_{w, \text { out }} h_{w, \text { out }} \\
\dot{Q}_{\text {in }} & =\dot{m}_{w \text {.in }} h_{w, \text { in }}
\end{aligned}
$$

where $\dot{m}_{w}$ denotes the mass flow rate of steam or water while $h_{w, \text { out }}$ and $h_{w, i n}$ refer to the enthalpy of outlet and inlet flows respectively.

$\dot{Q}_{a c c u m}$ is the energy accumulation inside a heating element which is produced by the change in temperature and mass of steam/water with time and is computed by below equation:

$$
\dot{Q}_{a c c u m}=\frac{\left(M_{s t}^{e} u_{s t}^{e}-M_{s t}^{i} u_{s t}^{i}\right)}{\Delta t}+\frac{\left(M_{w t}^{e} u_{w t}^{e}-M_{w t}^{i} u_{w t}^{i}\right)}{\Delta t}
$$

where $u$ stands for internal energy and $\Delta t$ represents the time step. Superscripts $e$ and $i$ refer to the end and the beginning of a time step [4].

During the transient operation of an HRSG, due to slow energy variation during a time interval in a heating element which is a control volume, SSSF process $\left(\mathrm{d} E_{c v} / \mathrm{d} t=0\right)$ was applied for the gas flow, as well as the water or steam flow in economizers and super heaters. However, due to large mass of water/steam mixture in evaporator and drum, and the high rate of energy variation due to boiling, USUF process was considered in the mass and energy analysis. Subsequently $\dot{Q}_{a c c u m}$ in (10) was set equal to zero for single phase flow (including gas/water/steam flows). However, for analyzing two-phase flow in evaporators and drums, the numerical value of $\dot{Q}_{\text {accum }}$ was computed from (10) [4].

$\dot{Q}_{b d}$ describes the amount of energy loss in drum due to blow down to keep the water inside the drum chemically balanced. The blow down mass flow rate was considered to be about $1 \%$ of water mass flow rate $\left(m_{b d}\right)$ entering the drum and was evaluated by following equation:

$$
\dot{Q}_{b d}=\dot{m}_{b d} h_{w t, b d}
$$

where $h_{w t, b d}$ denotes the enthalpy of saturated water in the drum.

To estimate the heat transfer rate between tube walls and steam/water, (12) can be used:

$$
\dot{Q}_{w}=U_{i} A_{i}\left(\tilde{T}_{m}-\tilde{T}_{w}\right)
$$

where $U i$ is the overall heat transfer coefficient computed based on the inner heat transfer surface area $\left(A_{i}\right)$ and $\tilde{T}_{w}$ is average steam/water temperature.

The mass conservation relation inside the drum and evaporator is:

$$
\frac{d\left(M_{w t}+M_{s t}\right)}{d t}=\dot{m}_{w t, \text { in }}-\dot{m}_{s t, o u t}
$$

where $M_{\mathrm{wt}}$ and $M_{\mathrm{st}}$ are the water and steam mass in evaporator, respectively. $\dot{m}_{w t, i n}$ indicates the water mass flow rate entering the evaporator and is estimated by (14) and (15) and $\dot{m}_{s t, o u t}$ is the mass flow rate of the steam flowing out of the drum and is computed by (16).

$$
\begin{gathered}
\dot{m}_{w t, i n, t+\Delta t}=\dot{m}_{w t, t}+K_{p} e(t)+K_{d} \frac{d e(t)}{d t} \\
e(t)=W(t)-W_{d}
\end{gathered}
$$




$$
\dot{m}_{s t, o u t}=\frac{K_{s t} p_{w}}{\sqrt{T_{w}}}
$$

$K_{p}$ and $K_{d}$ are related to HP and LP drum water level control system. The numerical values of these parameters were equal to $180 \mathrm{kgm}^{-1} \mathrm{~s}^{-1}$ and $9200 \mathrm{kgm}^{-1}$, respectively. $W l_{d}$ is computed from drum centerline and expressed in mm. In (16), $T_{w}$ and $P_{w}$ are the saturation temperature and pressure in the drum and $\dot{m}_{s t, o u t}$ is the steam mass flow rate out of drum at the steady-state operation. $K_{s t}$ was estimated 0.171 and 0.1999 for HP drum (HPB1) and LP drum (LPB), respectively; calculated from design results of system done by [7].

\subsection{Steam Turbine}

Because the response time of a steam turbine is known to be shorter than that of a HRSG, quasi-steady assumption could be applied to the steam turbine model [3].

While steam turbine is treated as a control volume, the following mass and energy equations are applied:

$$
V \frac{d \rho_{s t}}{d t}=\dot{m}_{s t, \text { in }}-\dot{m}_{s t, \text { out }}
$$

and

$$
V \frac{d(\rho E)_{s t}}{d t}=\dot{m}_{s t, \text { in }} h_{s t, \text { in }}-\dot{m}_{s t, \text { out }} h_{s t, \text { out }}-\dot{W}_{s t}
$$

$\rho$ is density and $e$ is energy; Also $V$ is volume and $\dot{W}_{s t}$ is shaft power. $\dot{m}_{s t, i n}$ and $\dot{m}_{s t, o u t}$ are steam turbine inlet and outlet mass flow rate, respectively.

The shaft power is evaluated from a quasi-steady assumption in (20). Also according to this assumption, (17) can be changed to (19).

$$
\begin{gathered}
\dot{m}_{s t, \text { in }}=\dot{m}_{s t, \text { out }} \\
\dot{W}_{s t}=\dot{m}_{s t, \text { in }}\left(h_{s t, \text { in }}-h_{s t, o u t}\right)
\end{gathered}
$$

Since the flow inside the turbine is fast enough, the quasi-steady assumption is quite reasonable. The condition of the turbine inlet is determined using the Stodola Ellipse Law for the off-design characteristics of turbines [2]. The Stodola Ellipse Law states:

$$
\frac{(\dot{m} \sqrt{T / p})_{\text {in }}}{(\dot{m} \sqrt{T / p})_{\text {in }, d}}=\frac{\sqrt{1-\left(p_{\text {out }} / p_{\text {in }}\right)^{2}}}{\sqrt{1-\left(p_{\text {out }} / p_{\text {in }}\right)^{2} d}}
$$

$T$ and $p$ represent temperature and pressure of turbine. The condensing pressure is assumed to be constant [2]. Subscripts $d$, in and out refer to design, inlet and outlet condition respectively.

The flow function is introduced, which is the modification of the earlier Stodola Ellipse Law considering the variation of the inlet condition. From this equation we could obtain section outlet pressure if we know the inlet mass flow rate, temperature, and pressure through the transient process of a steam turbine [3].

$$
\dot{m}_{s t, \text { in }}=k \sqrt{\frac{p_{s t, \text { in }}}{v_{s t, i n}}} \sqrt{1-\left(\frac{p_{s t, \text { out }}}{p_{s t, \text { in }}}\right)^{2}}
$$

$v$ represents specific volume, also subscript $s t$ refers to steam turbine. For steam turbine of present study, $k$ is equal to 0.148 .

\subsection{Condenser and miscellaneous devices}

Volume of a condenser is normally quite small and its response during transient process is very fast compared to that of HRSG. Thus, the assumption that the condenser is in a steady state at each time step can be applied. The overall heat transfer coefficient could be calculated from the HEI (Heat exchanger Institute) standard [9]. Heat exchange area was determined based on that coefficient and the off-design performance was estimated [10]. We also assume that the steam/water mixture introduced in the condenser is condensed to a 0 quality level. In addition, it is assumed that cooling water flow rate is constant at design value [3].

De-aerator and pump are considered to have high enough quick response time compared to the characteristics response time of the total system and no pressure drop in steam/water piping is considered [3]. 
Fig.1 Schematic view of designed combined cycle power plant with its system variables

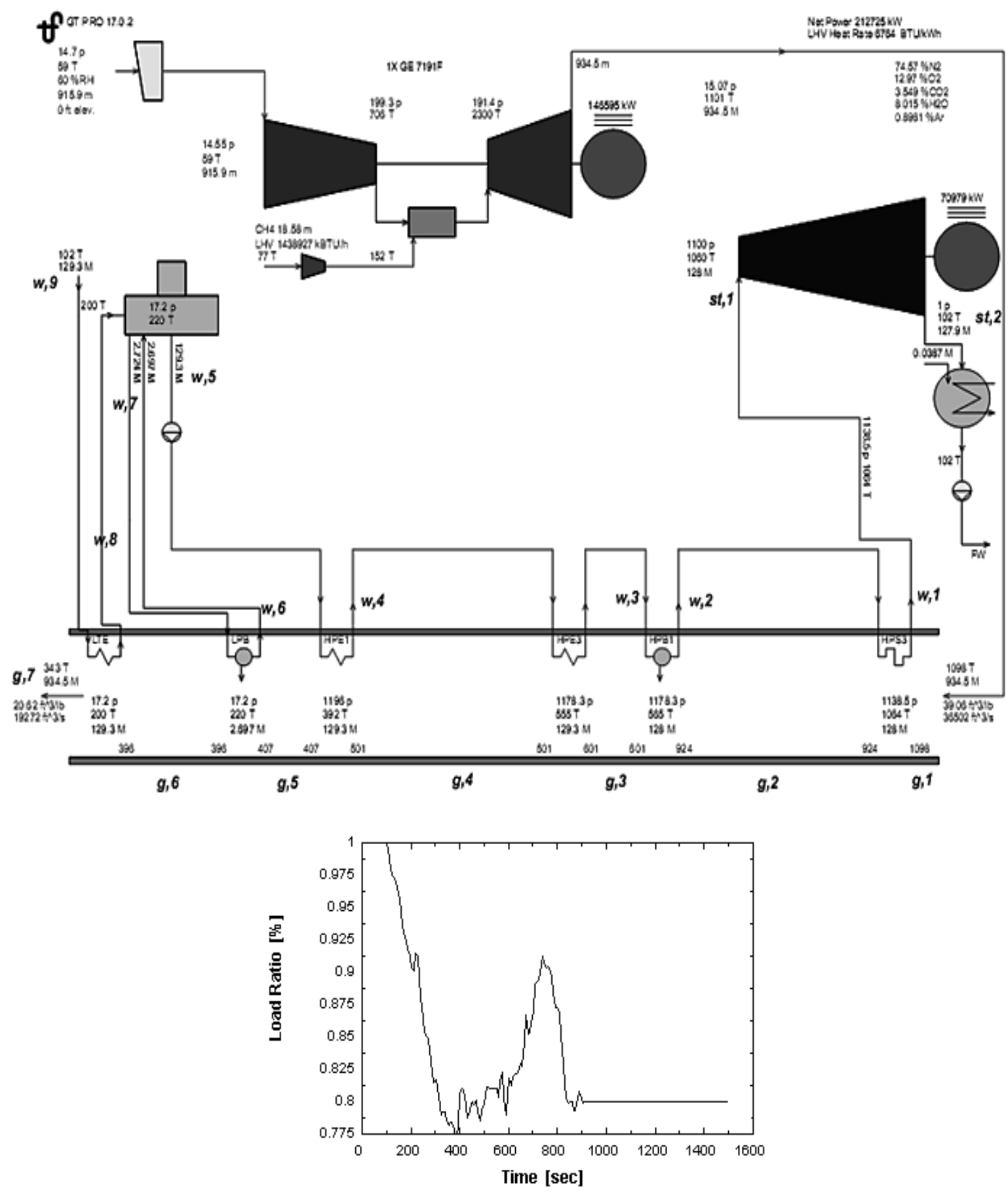

Fig.2 Variation of gas turbine partial load with time 


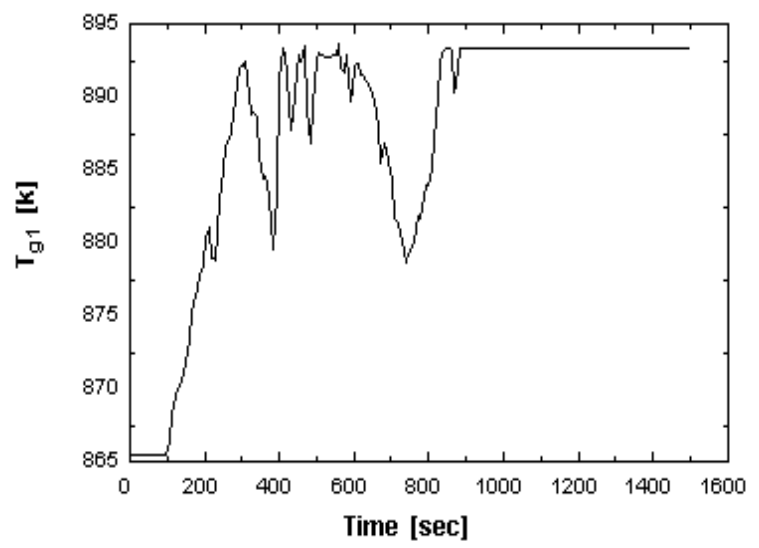

Fig.3 Variation of gas turbine flue gas temperature with time

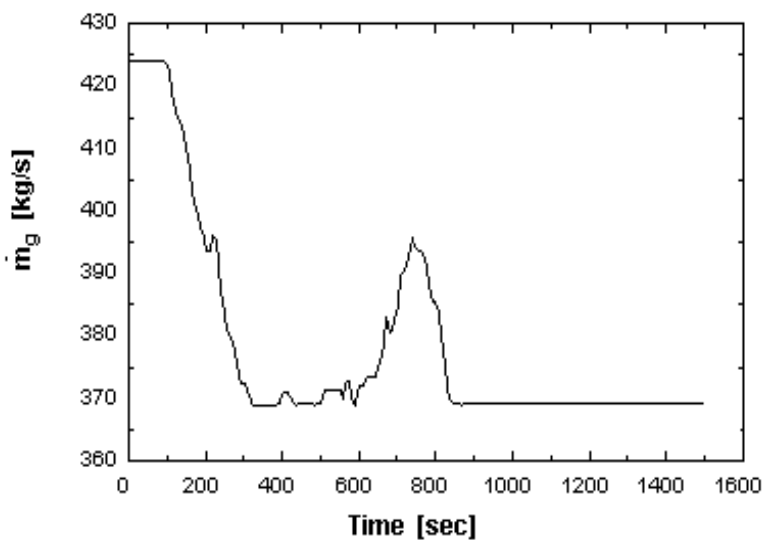

Fig.4 Variation of gas turbine flue gas mass flow rate with time

\section{NUMERICAL METHOD}

The system variables shown in Fig. 1 are solved simultaneously. The mentioned governing equations constructed a set of equations which were solved by forward finite difference method to get temperature of gas, tube wall and water/steam and also pressure of both drums at the end of each time interval.

To simplify solving the governing equations, the following points were considered:

a) In each time interval, enthalpy and thermo-physical properties of gas and steam/water were computed based on the average temperature in a time step.

b) There was no heat accumulation in HRSG duct, economizers and super heaters (as a control volume) during a time interval, therefore $\dot{Q}_{a c c u m}$ was set to zero in (7) [4].

Numerical evaluation of terms in (10) showed that $\dot{Q}_{a c c u m}$ was negligible in comparison with $\dot{Q}_{\text {out }}$ and $\dot{Q}_{\text {in }}$ in (7) during a time step (SSSF process). However, due to large mass of water/steam mixture in evaporator and drum and the high rate of energy variation due to boiling, the numerical values of heat accumulation computed from (10) were comparable with the corresponding numerical values of other terms in (7) during a time step (USUF process) [4].

\section{RESULTS AND DISCUSSIONS}

Governing equations set, imported to the mathematical software [8] and have been solved simultaneously. As results of modeling, that seen as the conclusions of load reduction in gas turbine, Fig.5, Fig.6, Fig.7, Fig.8, Fig.9 and Fig.10 can be considered.

In Fig.5 variation of output power of steam turbine with time, can be seen. As shown in this figure, load reduction in gas turbine causes decrease in steam turbine output power.

Metal temperature of elements in HRSG varies as shown in Fig.6 that is related to pre-heater (LTE), this temperature decreasing after a short increase in $t=150 \mathrm{sec}$.

Condenser temperature also decreases with time as shown in Fig.7 but more sharply in comparison with earlier figure. 
Variation of water level in HP drum (HPB1) is shown in Fig.8, low oscillation in this parameter obviously seen.

As result of load reduction of system, temperature of superheated steam exiting super heater of HRSG reduces with time that can be seen in Fig.9.

Finally Fig.10 and Fig.11 show variation of hot gas temperature exhausting HRSG stack and HP drum pressure with time respectively, decrease in this temperature can be seen as expected and drum pressure decreases along modeling time.

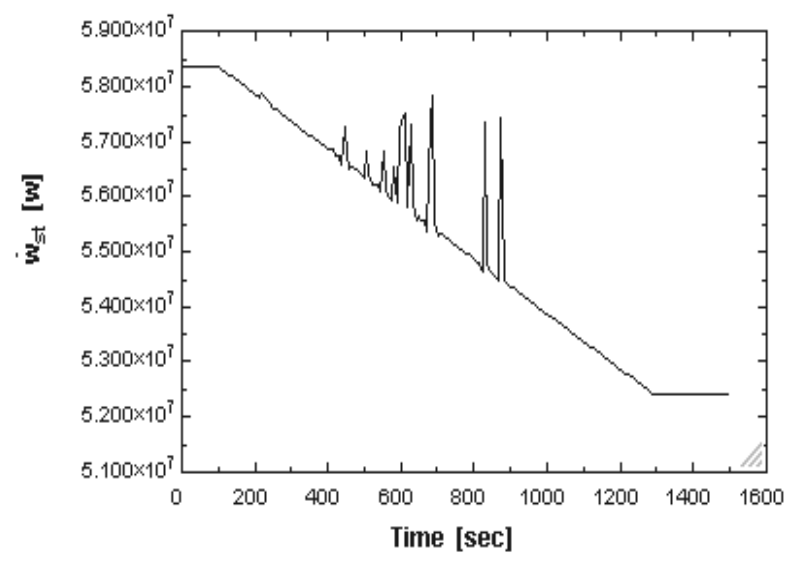

Fig. 5 Variation of steam turbine output power with time

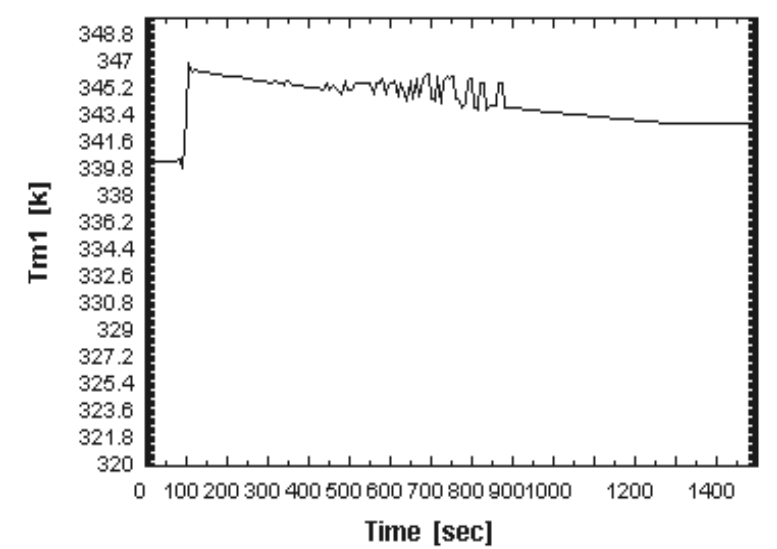

Fig.6 Variation of metal temperature of the preheater (LTE) with time

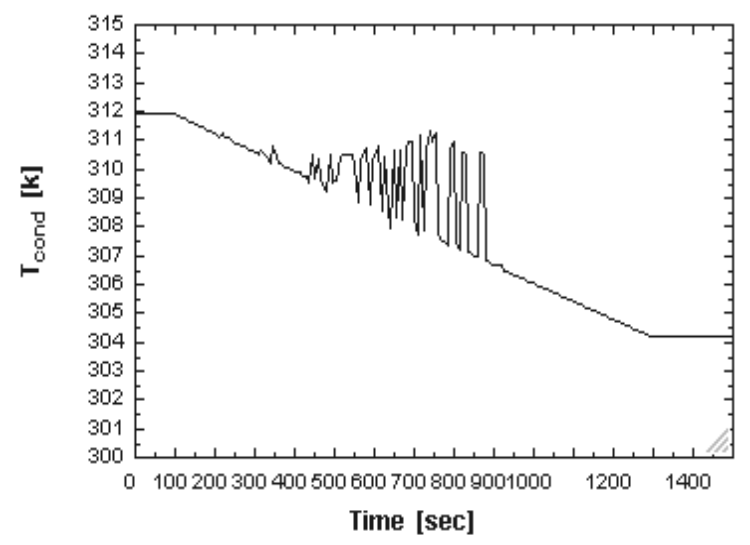

Fig.7 Variation of condenser temperature with time 


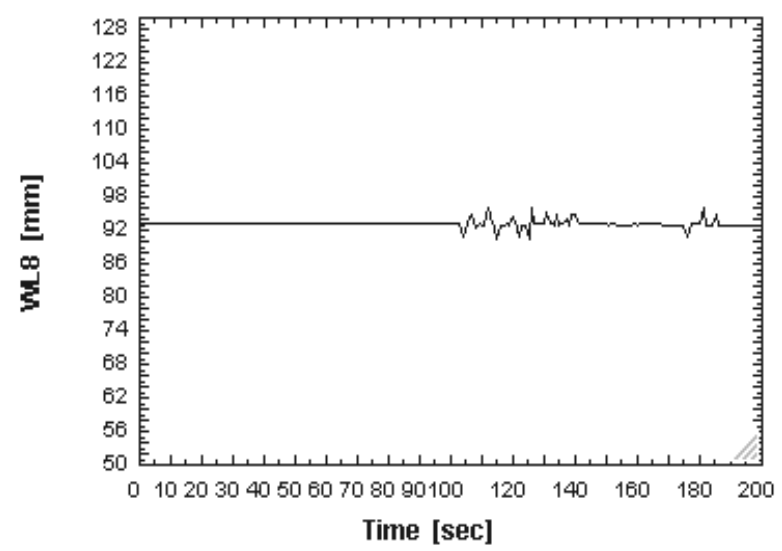

Fig.8 Variations in water level of HP drum (HPB1)

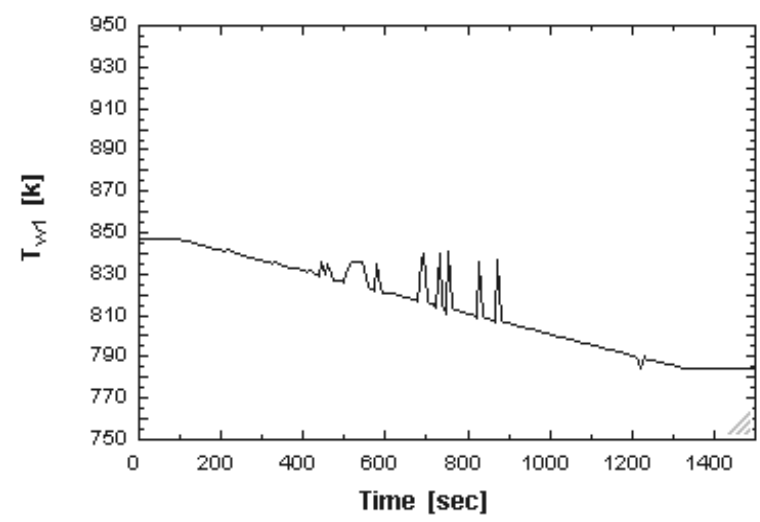

Fig.9 Variation of outlet steam temperature of super heater with time

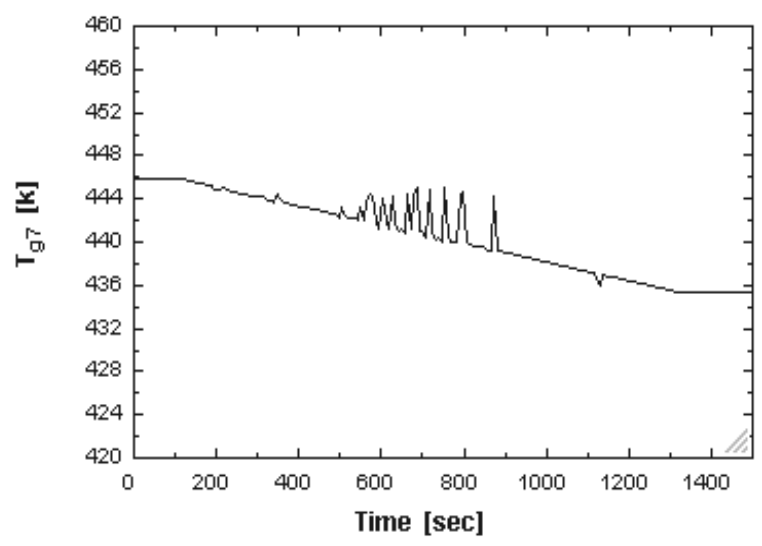

Fig.10 Variation of outlet flue gas of stack with time 


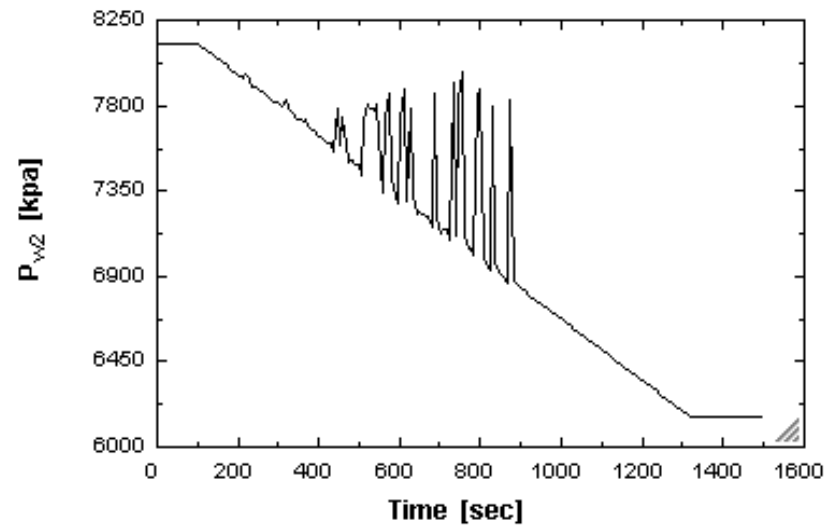

Fig.11 Variation of HP drum pressure with time

TABLE 1: SUMMARY OF DESIGN DATA OF CYCLE

\begin{tabular}{ll}
\hline \hline Gas turbine & GE7F \\
\hline Speed, rpm & 3600 \\
Electrical Power, Mw & 150 \\
Cycle Efficiency, \% & 34.5 \\
Outlet gas mass flow rate, kg/s & 423.65 \\
Outlet gas temperature, K & 867.05 \\
HRSG & Dual-pressure type \\
Stack temperature, K & 445.95 \\
Deaerator pressure, kpa & 118.59 \\
Feed water temperature, K & 312.04 \\
Outlet flow temperature of LTE, & 366.48 \\
K & $\begin{array}{l}\text { Single-pressure, } \\
\text { Condensing type, } \\
\text { Steam turbine }\end{array}$ \\
Without reheat \\
Gross output power, kw & 70979 \\
Input pressure, kpa & 7584.11 \\
Input temperature, K & 844.26 \\
Mass flow rate, kg/s & 58.06 \\
\hline \hline
\end{tabular}

\section{CONCLUSION}

A mathematical model for transient analysis of a combined cycle power plant was developed. Studied system was designed by the well-known commercial software geometrically and thermodynamically. This study considered load reduction in gas turbine as a dynamic behavior of cycle and its result have been shown in some figures. The figures show that load reduction as the input data cause to reduce the majority of output parameters exept of water level of drums. Knowing this results helps us to estimate mechanical and thermal stresses which are so important in power plant design and operation. For compeleting this study the results can be validated 
through comparing them with numerical output of a software like Thermoflow; this issue can be sobject of the next study.

\section{REFERENCES}

[1] F Alobaid., R Postler, J Strohle, B Epple, K Hyun-Gee. Modeling and investigation start-up procedures of a combined cycle power plant. Applied Energy vol. 4. 2008. 1173-1189.

[2] TS Kim, HJ Park, ST Ro,Characteristics of transient operation of a dual-pressure bottoming system for the combined cycle power plant. Energy vol. 26. 2001. 905-918.

[3] Shin JY, Jeon YJ, Maeng DJ, Kim JS, Ro ST.Analysis of the dynamic characteristics of a combinedcycle power plant. Energy vol. 27.2002. 1085-1098.

[4] S Sanaye, M Rezazadeh.Transient thermal modeling of heat recovery steam generators in combined cycle power plants. Int. J. Energy Res. vol. 31.2007. 1047-1063.

[5] KS Ahluwalia, R Domenichini. Dynamic Modeling of a Combined-Cycle Plant. ASME J Eng Gas Turbines Power vol. 112.1990. 164-167.

[6] JH Kim, TW Song, TS Kim, ST Ro.Model development and simulation of transient behavior of heavy duty gas turbines. ASME J Eng Gas Turbines Power vol. 123.2001. 589-594.

[7] Thermoflow Inc.GTPRO \& GTMASTER Ver 17.0.2, 2008.

[8] Engineering Equation Solver (EES), Commercial Version 6.883-3D, 2003.

[9] Heat Exchange Institute. HEI standards for steam surface condensers., $8^{\text {th }}$ ed Cleveland $(\mathrm{OH}: \mathrm{Heat}$ Exchange Institute Inc.) 1984.

[10] M.M.EL-Wakill, Power plant Technology, 1st ed. (McGraw -Hill,1985) ch 6. 288-291. 